\title{
The Effect of Quercetin in Corneal Opacity Induced by Mitomycin-C
}

\author{
*Correspondence to: \\ Lee YJ, \\ Tel: +82-53-810-3571 \\ Fax: +82-53-810-4618 \\ E-mail: yjlee-7447@hanmail.net \\ Received August 19, 2014 \\ Revised September 23, 2014 \\ Accepted September 24, 2014
}

\author{
Yoon Jeong Lee* \\ Department of Optometry \& Vision Science, Kyungwoon University, Gumi 730-739, Korea \\ Department of Life Sciences, Yeungnam University, Gyeongsan 712-749, Korea
}

Department of Life Sciences, Yeungnam University, Gyeongsan 712-749, Korea

\begin{abstract}
This study examined the effects of quercetin on corneal opacity caused by corneal edema by suppressing the damage on corneal endothelial cell, which was induced by mitomycin-C (MMC). In the MMC-treated group, the number of keratocytes was noticeably fewer compared to that of other groups. Although this group showed normal amount of fiber in the corneal stroma, the thickness was shown to be very thick and the alignment of the corneal endothelial cells that worked as the barrier against aqueous humor was irregular. According to such results, it was known that corneal opacity induced by MMC is not caused by proliferation of keratocytes, but by corneal edema triggered by the infiltration of aqueous humor. In the MMC+quercetin and quercetin+MMC-treated groups, the number of keratocytes was higher and polymorphonuclear leukocytes infilteration was lower significantly compared to that of the MMC-treated group. Although the amounts of fiber and endothelioid cell arrangement were normal, there was more space observed in the corneal stroma. Nonetheless, these groups showed significantly lower stromal thickness compared to that of the MMC group. In conclusion, quercetin has the effect on the reduction of corneal opacity caused by corneal edema that work MMC-induced damage to the corneal endothelial cells.
\end{abstract}

Key Words: Quercetin, Mitomycin-C, Corneal opacity, Corneal edema, Endothelial cell

\section{INTRODUCTION}

Today, the number of people seeking a corrective eye surgery has been on the rise due to the development of numerous refractive corneal surgery methods such as photorefractive keratectomy (PRK; excimer laser), laser in situ keratomileusis (LASIK), and laser assisted sub-epithelial keratomileusis (LASEK). In line with this, surgical methods and instruments are rapidly being developed in order to reduce post-surgery pain, corneal opacity, and complications that may cause considerable disabilities to eyesight and as a consequence, patients receive a surgery relying into the greatly improved surgical stability. However, corneal opacity has been pinpointed as one of the main side effects shown after a refractive corneal surgery.

The most common causes of postoperative corneal opacity are proliferation of keratocytes or corneal edema caused by aqueous humor influx, which is triggered by the increased permeability of the corneal endothelial cells (Majmudar et al., 2000; Xu et al., 2001; Carones et al., 2002; Chang, 2004; Natto et al., 2005). In order to reduce postoperative corneal opacity by suppressing proliferation of keratocytes based on induced apoptosis, mitomycin-C (MMC) in low concentrations below $0.02 \%$ is applied for $1 \sim 2$ minutes in the procedure of a corneal refractive surgery (Majmudar et al., 2000; Xu et al., 2001; Carones et al., 2002; Natto et al., 2005). This method is reported to be particularly effective in high myopia patients undertaking PRK surgery and patients with low corneal thickness to receive a LASIK surgery, as it noticeably decreases corneal opacity by suppressing the proliferation and vitalization of keratocytes during recovery (Hashemi et al., 2004).

Derived from Streptomyces caespitosus, MMC controls mitosis and proliferation of various cells such as capillary endothelial cells, corneal endothelial cells, corneal epithelial cells, conjunctival fibroblasts, and Tenon's capsule fibroblasts

(a) This is an open-access article distributed under the terms of the Creative Commons Attribution Non-Commercial License (http://creativecommons.org/licenses/by-nc/3.0) which permits unrestricted noncommercial use, distribution, and reproduction in any medium, provided the original work is properly cited.

Copyrights @ 2014 by Korean Society of Microscopy 
(Jampel, 1992; Khaw et al., 1992; Smith et al., 1994) by suppressing protein synthesis based on inhibition of nucleic acid synthesis and control of alkylation (Crooke \& Bradner, 1976; Smith et al., 1994). For these reasons, MMC is widely used in refractive surgeries and other corrective eye surgeries. It is known as a supplementation treatment that prevents epulosis after a glaucoma surgery due to fibroblast proliferation, treats pterygium recurrence characterized by fibrovascular proliferation in the conjunctiva (Crowston et al., 2006), suppresses proliferative vitreoretinopathy (Kim et al., 2002), and improves success of endonasal dacryocystorhinostomy (Kim \& Chung, 2002).

Nonetheless, MMC is also reported to induce several complications that may lead to serious visual impairment including secondary glaucoma that is shown in a pterygium surgery after MMC use, corneal edema, corneal perforation, iritis, photophobia, and pain (Rubinfeld et al., 1992; Fujitani et al., 1993). High concentration or prolonged use of MMC may result in corneal opacity as it causes edemas in the corneal tissue and it requires considerable time to recover normal eyesight or cornea form (Kim et al., 2008). It is known that occurrence of edema-induced corneal opacity is triggered by the apoptosis of the corneal endothelial cells, where MMC works to prevent introduction of aqueous humor at the anterior chamber into the corneal tissue (Chang, 2004), or damage on the metabolism pumping function by the suppressed $\mathrm{Na}^{+} / \mathrm{K}^{+}$-ATPase of the corneal endothelial cells (Kim \& Bae, 2000). Such implies that corneal opacity with another mechanism may be induced by MMC and it must be treated to reduce corneal opacity during a surgery.

Numerous efforts have been made to selectively suppress MMC's effects on the corneal endothelial cells in a refractive surgery. Quercetin, a non-toxic flavonoid, has been reported as a substance that interferes with edema by protecting endothelial cells based on its anti-inflammatory and antioxidative function (Guardia et al., 2001; Reiterer et al., 2004).

Quercetin (3,3', 4', 5, 7-penthydroxy flavone) is a core component of the flavonoid family (Kuhnau, 1976; Anton, 1988) found in onions, fruits, vegetables, olive oil, red wine, and tea (Hertog et al., 1993). Average daily intake of flavonoids through food and nutritional supplements are reported to be about $1 \mathrm{~g}$ (Brown, 1980), and consumption of quercetin through supplements is on the rise following the reports of its dynamic pharmacological activities. Quercetin is known to have antimicrobial, antiviral, antiulcerogenic, cytotoxic, antineoplastic, mutagenic, anti-inflammatory, antioxidant, antihepatotoxic, antihipertensive, hypolipidemic and antiplatelet activities (Formica \& Regelson, 1995).

In particular, quercetin displays powerful inhibitory effect when it comes to proliferation of keloid fibroblast and collagen production (Lisi et al., 2010) and especially, the flavonoids (quercetin, kaempferol) extracted from onions are known to reduce scar formation by inhibiting the vitality of fibroblasts (Cho, 2010).

Based on these findings, this study attempts to assess the effect of quercetin in terms of corneal opacity reduction caused by edema by suppressing the corneal endothelial damage induced by MMC.

\section{MATERIALS AND METHODS}

\section{Animals and Reagents}

The laboratory animals used for the experiment were Sprague-Dawley white rats obtained from the Daehan Bio Link (Korea). The rats were obtained one week prior to the experiment to allow sufficient time for adaptation, and healthy ones that weighed between 250 270 g were used for the experiment. The rats were cared for under an environment with $50 \% \pm 10 \%$ of humidity and $25^{\circ} \mathrm{C} \pm 1^{\circ} \mathrm{C}$ of temperature and an automatic lighting system that was employed to provide sufficient light in a 12-hour cycle. All animals were given free access to water and food. All chemical agents including MMC and quercetin (3, 3', 4', 5, and 7-penthydroxy flavone) were purchased from Sigma-Aldrich Inc. (USA).

\section{MMC and Quercetin Administration}

According to the method implemented in the study of Escariao et al. (2008), the corneal epithelial scrape injury model was applied to rats. MMC that was dissolved in saline solution with $2.0 \%$ concentration was administered to the rats' eyes for 2 minutes while intraperitoneally administering quercetin, which was dissolved in soybean oil, in the total volume of $10 \mathrm{mg} / \mathrm{kg}$. The experiment was conducted after classifying the subjects into the control group (Control group, $\mathrm{n}=2$ ), group administered with MMC (MMC group, $\mathrm{n}=8$ ), group administered with quercetin after MMC (MMC+Quer group, $\mathrm{n}=8$ ), group administered with $\mathrm{MMC}$ after quercetin (Quer+MMC group, $\mathrm{n}=8$ ), and group administered only with quercetin (Quer group, $\mathrm{n}=6$ ) (Table 1).

Table 1. Classification of experimental groups

\begin{tabular}{ll}
\hline \multicolumn{1}{c}{ Group (n) } & \multicolumn{1}{c}{ Characteristic } \\
\hline Control (2) & No treatment \\
MMC (8) & MMC 2.0\% \\
Quer (6) & Quercetin $10 \mathrm{mg} / \mathrm{kg}$ \\
Quer+MMC (8) & Quercetin $10 \mathrm{mg} / \mathrm{kg}+$ MMC $2.0 \%$ \\
MMC+Quer (8) & MMC 2.0\%+quercetin $10 \mathrm{mg} / \mathrm{kg}$ \\
\hline
\end{tabular}

MMC, mitomycin-C; Quer, quercetin. 


\section{Histological Observation}

\section{Production of paraffin blocks and slides}

The laboratory animals were anesthetized with ketamine hydrochloride $(60 \mathrm{mg} / \mathrm{kg})$ and xylazine $(10 \mathrm{mg} / \mathrm{kg})$ and killed, and then their eyes were enucleated. The enucleated eyeballs were fixed and preserved in 10\% phosphate buffered (neutral) formalin and were washed with running water. For embedding, the alcohol concentration was gradually increased for dehydration, and xylene was used to remove excess alcohol. The produced paraffin blocks were sectioned in thickness of $4 \sim 5 \mu \mathrm{m}$ by using a microtome (model 45 ; Lipshaw Corp., USA) to produce slides.

\section{H\&E staining}

H\&E staining was conducted to observe general changes to the corneal epithelium and assess the number of keratocytes, infiltration of polymorphonuclear leukocyte (PMN), and stromal thickness. The tissue samples selected in $4 \sim 5 \mu \mathrm{m}$ of thickness were stained with $\mathrm{H} \& \mathrm{E}$ and mounted. These were then observed with an optical microscope (BH-2; Olympus, Japan).

\section{Mason's trichrome staining}

Mason's trichrome staining was conducted for the formative observation of the collagenous fibers created by keratocytes. The tissue sample sectioned in $4 \sim 5 \mu \mathrm{m}$ of thickness were placed in $56^{\circ} \mathrm{C}$ Bouin solution for 1 hour to accelerate the staining process and then washed. The slide was immersed in Weigert iron hematoxylin solution for 10 minutes, in Biebrich scarlet-acid fuchsin solution for 2 minutes, in phosphomolybdic-phosphotungstic acid solution for 10 15 minutes, and in aniline blue solution for 5 minutes. After these, the samples were washed. The samples were then immersed in $0.5 \%$ glacial acetic acid solution for 3 5 minutes and mounted. These were observed with an optical microscope (BH-2; Olympus).

\section{Immunohistochemical staining for PCNA}

Immunohistochemical staining was conducted for the formative observation of the cell proliferation in the cornea. After hydration process for the tissue sample sectioned in $4 \sim 5 \mu \mathrm{m}$ of thickness, the sample was treated in the solution that was diluted with anti-proliferating cell nuclear antigen (PCNA) monoclonal antibody (Biodesign M01103M; Sigma, USA) at 1:50 dilution for 20 hours at $4^{\circ} \mathrm{C}$. After washing it with phosphate buffered saline (PBS, pH 7.4), the sample was reacted in anti-mouse IgG Ab (Sigma M9902; Sigma) at 1:100 dilution for 40 minutes under room temperature, followed by additional treatment in peroxidase anti-peroxidase complex (in mouse, Sigma P2416; Sigma) at 1:100 dilution for 40 minutes. Then, coupler was made by adding $0.045 \%$ of hydrogen peroxidase to the $0.025 \%$ 3, 3'-diaminobenzidine solution that was dissolved in PBS and in use of this coupler, chromogenic reaction of the sample was assessed under room temperature for 3 minutes. After counterstaining the final sample with hematoxylin, it was mounted. These were then observed with an optical microscope (BH-2; Olympus).

\section{Cell Count}

A cell count was conducted to calculate the number of keratocytes and extent of PMN infiltration. After staining the tissue sample sectioned in $4 \sim 5 \mu \mathrm{m}$ of thickness with H\&E, it was mounted. These were then observed with an optical microscope (BH-2; Olympus). The microscope was set to a $\times 40$ magnification, and the number of cells were counted in area/field $=0.018 \mathrm{~mm}^{2}$ to yield the average count of cells.

\section{Statistical Analysis}

For statistical assessment, SPSS for Windows version 14.0 (SPSS Inc., Chicago, IL, USA) was implemented while the 95\% confidence interval was obtained through ANOVA.

\section{RESULTS}

\section{Changes in the Number of Keratocytes and PMN Cells}

The total count of keratocytes composing the corneal stroma is as shown in Table 2.

The number of keratocytes was noticeably fewer $(\mathrm{p}<0.05)$ in the MMC group and MMC+Quer group $(\mathrm{p}<0.05)$ compared to that of other groups while the Quer+MMC group and Quer group showed significantly fewer count compared to that of the Control group $(\mathrm{p}<0.05)$.

The total count of PMN cells embedded in the corneal stroma is as shown in Table 2.

The number of PMN cell was particularly high in the MMC group $(\mathrm{p}<0.05)$ compared to that of other groups while the MMC+Quer group and Quer+MMC group showed

Table 2. Changes of morphological signs

\begin{tabular}{lccc}
\hline \multicolumn{1}{c}{ Groups } & $\begin{array}{c}\text { Number of } \\
\text { keratocyte }\end{array}$ & $\begin{array}{c}\text { PMN cell } \\
\text { infiltration }\end{array}$ & $\begin{array}{c}\text { Stromal } \\
\text { thickness }\end{array}$ \\
\hline Control & $13.63 \pm 1.15^{*}$ & $0.00 \pm 0.00^{*}$ & $146.67 \pm 2.91^{*}$ \\
MMC & $10.04 \pm 0.60^{\dagger}$ & $6.30 \pm 0.69^{\dagger}$ & $238.62 \pm 12.80^{\dagger}$ \\
MMC+Quer & $10.95 \pm 0.49^{\ddagger}$ & $2.57 \pm 0.47^{\dagger}$ & $212.58 \pm 9.05^{\dagger}$ \\
Quer+MMC & $12.50 \pm 0.65^{\ddagger}$ & $2.08 \pm 0.30^{\ddagger}$ & $215.95 \pm 11.04^{\dagger}$ \\
Quer & $12.02 \pm 0.52^{*}$ & $0.46 \pm 0.09^{*}$ & $171.89 \pm 6.57^{*}$ \\
\hline
\end{tabular}

Statistical analysis was by a one-way ANOVA with Tukey's test.

Values are presented as mean \pm standard error for rats in each group.

Values with different superscripts are significantly different $(\mathrm{p}<0.05)$.

Area: $0.018 \mathrm{~mm}^{2}$.

PMN, polymorphonuclear leukocytes; MMC, mitomycin-C; Quer, quercetin. 
significantly higher count compared to that of the Control group and Quer group $(\mathrm{p}<0.05)$.

\section{Change in the Thickness of Corneal Stroma}

The change in the thickness of the corneal stroma is as shown in Table 2.

The MMC group showed particularly high stromal thickness compared to that of other groups $(\mathrm{p}<0.05)$ while the MMC+Quer group and Quer+MMC group showed significantly lower thickness compared to that of the MMC group $(\mathrm{p}<0.05)$.

\section{Histological Observation}

\section{H\&E staining}

The Control group and Quer group showed normally preserved corneal tissue (Fig. 1A and E). The MMC group showed formation of vacuole in epithelium and stroma, and the stromal thickness increased significantly with numerous inflammatory cell infiltrations. Also, the corneal endothelial cells were not properly aligned (Fig. 1B). Although the MMC+Quer group and Quer+MMC group showed a tissue formation that is relatively similar to that of the Control group showing normally preserved corneal tissue, the corneal stroma was slightly thicker and a small amount of inflammatory cell infiltration was observed in its topmost layer (Fig. 1C and D).

\section{Mason's trichrome staining}

The Control group and Quer group showed normally preserved corneal tissue (Fig. 2A and E). The MMC group showed significant cell proliferation in the basal layer of the corneal epithelia. Although the amount of fiber was normal in the corneal stroma, more space was observed within the corneal stroma, resulting in greater thickness (Fig. 2B). The $\mathrm{MMC}+$ Quer group and Quer+MMC group showed normal keratocyte count and fiber count similar to that of the Control group; however, more space was observed between the cells and fiber of corneal stroma, resulting in greater thickness (Fig. $2 \mathrm{C}$ and $\mathrm{D})$.

\section{Immunohistochemical staining for PCNA}

The corneal tissue of the Control group showed normally preserved pattern (Fig. 3A). The MMC group showed significant cell proliferation in the basal layer of the corneal epithelia and numerous vacuoles were observed in the corneal stroma. However, no keratocytes were observed (Fig. 3B). The $\mathrm{MMC}+$ Quer group, Quer+MMC group, and Quer group

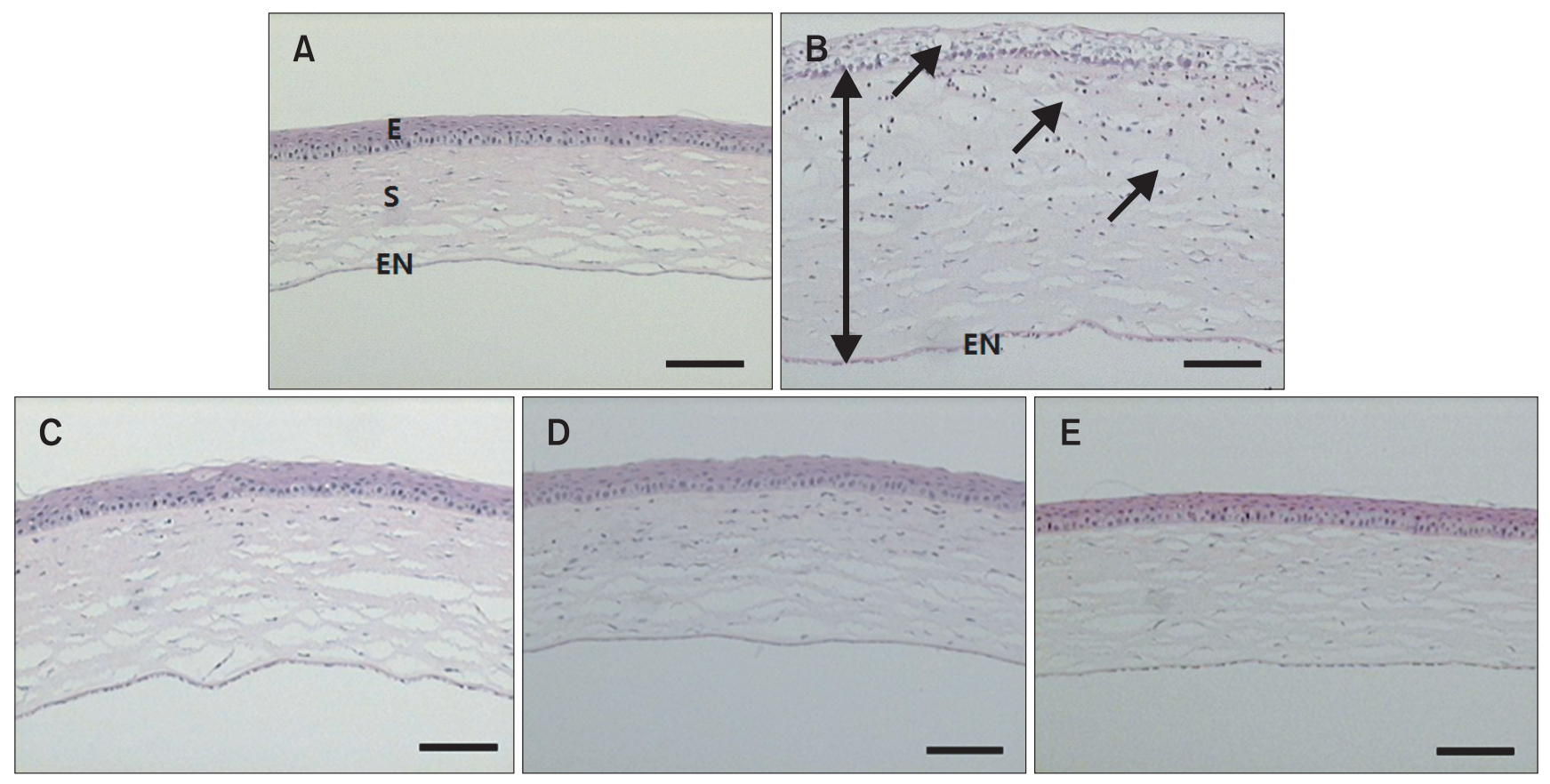

Fig. 1. Histopathologic changes of the cornea (H\&E stain, scale bars $=100 \mu \mathrm{m})$. (A) In control rat, the cornea architectures were well preserved. (B) In mitomycin-C (MMC) treated rat, the formation of vacuole were observed in epithelium and stroma (arrows). The stromal thickness increased significantly with numerous inflammatory cell infiltrations. The corneal endothelial cells were not properly aligned. (C) In MMC+quercetin (Quer) treated rat, the cornea architectures were relatively well preserved. The corneal stroma was slightly thicker and a small amount of inflammatory cell infiltration was observed in its topmost layer. (D) In Quer+MMC treated rat, the cornea architectures were relatively well preserved. The corneal stroma was slightly thicker and a small amount of inflammatory cell infiltration was observed in its topmost layer. (E) In quercetin treated rat, the cornea architectures were well preserved. E, stratified squamous epithelium; S, stroma; EN, endothelium. 


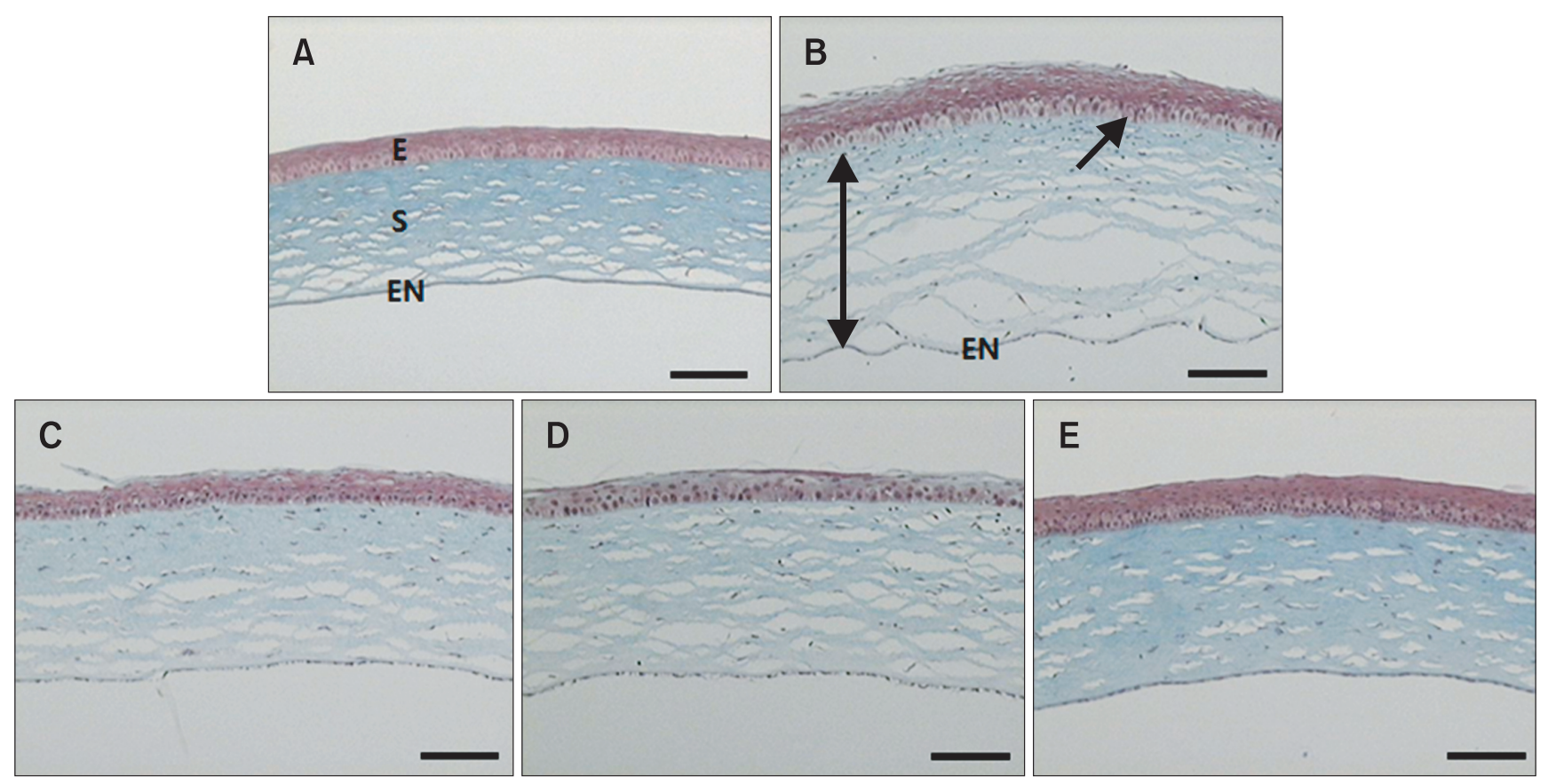

Fig. 2. Histopathologic changes of the cornea (Mason's trichrome stain, scale bars=100 $\mu \mathrm{m}$ ). (A) In control rat, the cornea architectures were well preserved. (B) In mitomycin-C (MMC) treated rat, the proliferation of cells were observed in the basal layer of the corneal epithelia (arrow). The amount of fiber was normal in the corneal stroma, more space was observed within the corneal stroma, resulting in greater thickness. (C) In MMC+quercetin (Quer) treated rat, the cornea architectures were relatively well preserved. The count of keratocyte and fiber was normal. The space was observed between the cells and fiber of corneal stroma, resulting in greater thickness. (D) In Quer+MMC treated rat, the cornea architectures were relatively well preserved. The count of keratocyte and fiber was normal. The space was observed between the cells and fiber of corneal stroma, resulting in greater thickness. (E) In quercetin treated rat, the cornea architectures were well preserved. E, stratified squamous epithelium; S, stroma; EN, endothelium.

were relatively well preserved and showed similar structure to the Control group; however, noticeable cell proliferation was observed at the basal layer of the corneal epithelia (Fig. 3C-E).

\section{DISCUSSION}

The most common causes of corneal opacity shown after a refractive eye surgery are proliferation of keratocytes or corneal edema caused by aqueous humor influx, which is triggered by the increased permeability of the corneal endothelial cells (Majmudar et al., 2000; Xu et al., 2001; Carones et al., 2002; Chang, 2004; Natto et al., 2005). According to the results derived in this study, the corneal edema that is generated by administering excessive MMC can be pertained to the latter case. In the group administered with MMC, the number of keratocytes was relatively fewer compared to that of other groups $(\mathrm{p}<0.05)$. Although its histological observation revealed normal amount of fiber, greater thickness was observed due to the formation of vacuoles within the corneal stroma $(p<0.05)$. Also, the corneal endothelial cells that worked as the barrier against aqueous humor were not properly aligned. Thus, it is known that corneal opacity occurs due to corneal edema caused by invasion of aqueous humor. Furthermore, significant infiltration of PMN, which are inflammatory cells, was observed throughout the corneal stroma $(\mathrm{p}<0.05)$; therefore, it is speculated that localized edema was accompanied as a consequence.

The results of this study confirmed previous reports that the use of MMC to the patients who have very thin stromal thickness and about to undergo a LASIK surgery significantly reduced corneal opacity during recovery by suppressing proliferation and vitalization of keratocytes (Hashemi et al., 2004). The study failed to verify the injury mechanism of the corneal endothelial cells as claimed by the various studies that reported suppression of mitosis and proliferation of corneal endothelial cells by MMC (Smith et al., 1994), damage on the metabolism pumping function due to repressed $\mathrm{Na}^{+} /$ $\mathrm{K}^{+}$-ATPase by the corneal endothelial cells (Kim \& Bae, 2000), and edema generated in the corneal stroma caused by aqueous humor influx, which is triggered by the increased permeability of the corneal endothelial cells (Chang, 2004). However, the irregular alignment of the corneal endothelial cells implies presence of damage and in consideration of such assumption, corneal opacity is believed to be induced due to corneal edema incurred by the increased permeability of aqueous humor.

However, the cells with high proliferation that showed strong positive PCNA reaction in the MMC group were 


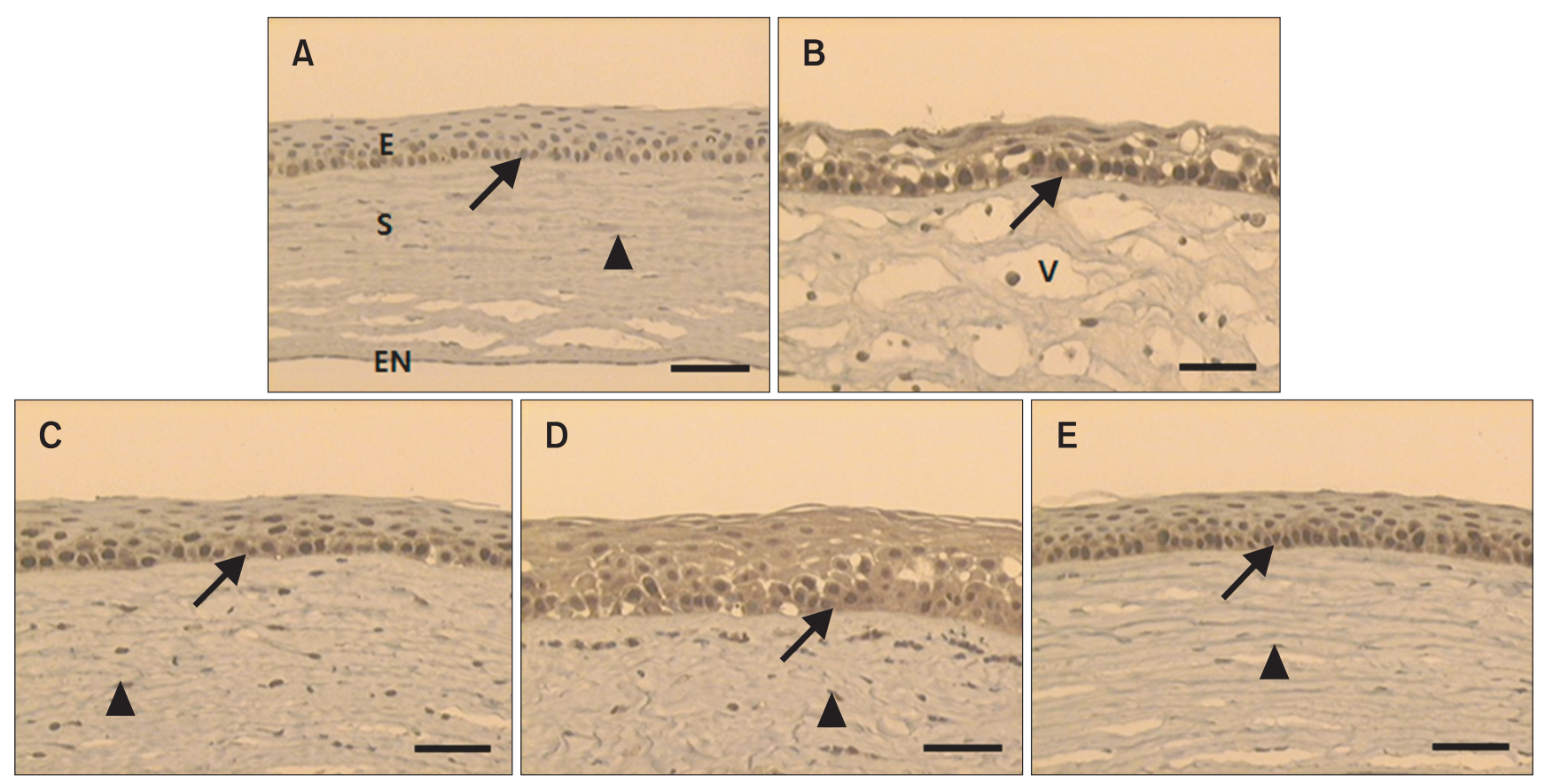

Fig. 3. Histopathologic changes of the cornea (immunohistochemistry stain, scale bars=50 $\mu \mathrm{m}$ ). (A) In control rat, the cornea architectures were well preserved. Basal cell (arrow), keratocyte (arrowhead). (B) In mitomycin-C (MMC) treated rat, the proliferation of cells were observed in the basal layer of the corneal epithelia. The numerous vacuoles were observed in the corneal stroma. No keratocytes were observed. (C) In MMC+quercetin (Quer) treated rat, the cornea architectures were relatively well preserved. The proliferation of cells were observed noticeably in the basal layer of the corneal epithelia (arrow). The shape and count of keratocyte was observed normally in the corneal stroma (arrowhead). (D) In Quer+MMC treated rat, the cornea architectures were relatively well preserved. The proliferation of cells were observed noticeably in the basal layer of the corneal epithelia (arrow). The shape and count of keratocyte was observed normally in the corneal stroma (arrowhead). (E) In quercetin treated rat, the cornea architectures were well preserved. The proliferation of cells were observed noticeably in the basal layer of the corneal epithelia (arrow). The shape and count of keratocyte was observed normally in the corneal stroma (arrowhead). E, stratified squamous epithelium; S, stroma; EN, endothelium; V, vacuoles.

from the basal layer of the corneal epithelia, and such showed contradictory result from a study that reported MMC's function to suppress mitosis and proliferation of corneal epithelial cells (Smith et al., 1994). Among various phenomena that appeared in the course of corneal epithelial cell's recovery, a possible explanation of such difference can be found from the presence of epidermal growth factor (EGF) receptor in the membrane of the basal epithelial cells. It seems to be related to the induced formation of new tissue to the wounded area as it accelerates cell proliferation, realignment, and redistribution (Buckley-Sturrock et al., 1989; Zyzak et al., 1994).

In the MMC+Quer group and Quer+MMC group, the number of keratocytes was higher compared to that of the MMC group $(\mathrm{p}<0.05)$. Since quercetin is known for its strong inhibitory effects when it comes to proliferation of keloid fibroblast, which is a type of keratocyte in the corneal stroma, and production of collagen (Lisi et al., 2010), and reduction of scar formation by inhibiting the activities of keloid fibroblast (Cho et al., 2010). Along with MMC, quercetin was expected to generate synergy effect to decrease the number of keratocytes; however, the group treated with both MMC and quercetin showed higher keratocyte count compared to the MMC group $(\mathrm{p}<0.05)$, and only significant decrease was shown in comparison with that of the Control group $(p<0.05)$. This group also showed noticeably less infiltration of PMN cells compared to that of the MMC group $(\mathrm{p}<0.05)$. According to the histological observation, the amount of fiber and endothelial alignment in the corneal stroma were normal, which was similar to that of the control group; however, more space was observed between the cell and fiber within the corneal stroma, and it resulted in greater thickness $(\mathrm{p}<0.05)$. Nevertheless, the stromal thickness was significantly lower compared to that of the MMC group ( $\mathrm{p}<0.05)$. Quercetin is reported to have antibacterial, antiviral, anti-inflammatory, and antioxidative effects (Formica \& Regelson, 1995; Guardia et al., 2001; Reiterer et al., 2004). In consideration of such performance of quercetin, the above results derived in the study can be interpreted as quercetin suppressed MMC's mechanisms through its anti-inflammatory effects, which reduced infiltration and edema of PMN, the representative symptoms of acute inflammation, and its antioxidative effects, which protected the endothelial cells from oxidative stress induced by inflammation. 
The MMC+Quer group and Quer+MMC group showed similar results and aspects with regards to keratocyte count, PMN cell count, strong positive cell reaction to PCNA, stromal thickness, and histological observation. As such, it is considered that the order of treatment when using both quercetin and MMC does not cause significant difference. MMC treatment is essential in a refractive eye surgery to inhibit proliferation of keratocytes and thus prevent corneal opacity. However, it may cause corneal opacity due to the formation of corneal edema. Through the experiment, the study proved reduction of possible corneal opacity caused by corneal edema that work MMC-induced damage to the corneal endothelial cells.

\section{CONCLUSIONS}

By taking quercetin before or after surgery and in everyday routine, it is expected to reduce the occurrence of corneal opacity that is a side-effect of a corneal refractive surgery, as it reduces possible chance of aqueous humor influx, thus preventing MMC-induced damage to the corneal endothelial cells.

\section{CONFLICT OF INTEREST}

No potential conflict of interest relevant to this article was reported.

\section{REFERENCES}

Anton R (1988) Flavonoids and traditional medicine. Prog. Clin. Biol. Res. 280, 423-439.

Brown J P (1980) A review of the genetic effects of naturally occurring flavonoids, anthraquinones and related compounds. Mutat. Res. 75, 243-277.

Buckley-Sturrock A, Woodward S C, Senior R M, Griffin G L, Klagsbrun M, and Davidson J M (1989) Differential stimulation of collagenase and chemotatic activity in fibroblasts derived from rat wound repair tissue and human skin by growth factors. J. Cell. Physiol. 138, 70-78.

Carones F, Vigo L, Scandola E, and Vacchini L (2002) Evaluation of the prophylactic use of mitomycin-C to inhibit haze formation after photorefractive keratectomy. J. Cataract Refract. Surg. 28, 20882095.

Chang S W (2004) Early corneal edema following topical application of mitomycin-C. J. Cataract Refract. Surg. 30, 1742-1750.

Cho J W, Cho S Y, Lee S R, and Lee K S (2010) Onion extract and quercetin induce matrix metalloproteinase-1 in vitro and in vivo. Int. J. Mol. Med. 25, 347-352.

Crooke S T and Bradner W T (1976) Mytomycin C : a review. Cancer Treat. Rev. 3, 121-139.

Crowston J G, Wang X Y, Khaw P T, Zoellner H, and Healey P R (2006) Human serum reduces mitomycin-C cytotoxicity in human tenon's fibroblasts. Invest. Ophthalmol. Vis. Sci. 47, 946-952.

Escariao A C, Nagasaki T, Zhao J, and Braunstein R (2008) Effects of mitomycin $\mathrm{C}$ on infiltration of polymorphonuclear leukocytes after epithelial scrape injury in the mouse cornea. Arq. Bras. Oftalmol. 71, 822-826.

Formica J V and Regelson W (1995) Review of the biology of quercetin and related bioflavonoids. Food Chem. Toxicol. 33, 1061-1080.

Fujitani A, Hayasaka S, Shibuya Y, and Noda S (1993) Corneoscleral ulceration and corneal perforation after pterygium excision and topical mitomycin C therapy. Ophthalmologica 207, 162-164.

Guardia T, Rotelli A E, Juarez A O, and Pelzer L E (2001) Anti-inflammatory properties of plant flavonoids. Effects of rutin, quercetin and hesperidin on adjuvant arthritis in rat. Farmaco 56, 683-687.

Hashemi H, Taheri S M, Fotouhi A, and Kheiltash A (2004) Evaluation of the prophylactic use of mitomycin- $C$ to inhibit haze formation after photorefractive keratectomy in high myopia: a prospective clinical study. BMC Ophthalmol. 4, 12.

Hertog M G, Hollman P C, Katan M B, and Kromhout D (1993) Intake of potentially anticarcinogenic flavonoids and their determinants in adults in The Netherlands. Nutr. Cancer 20, 21-29.

Jampel H D (1992) Effect of brief exposure to mitomycin C on viability and proliferation of cultured human Tenon's capsule fibroblasts. Ophthalmology 99, 1471-1476.

Khaw P T, Sherwood M B, Mackay S L, Rossi M J, and Schultz G (1992) Five-minute treatments with fluorouracil, floxuridine, and mitomycin have long-term effects on human Tenon's capsule fibroblasts. Arch. Ophthalmol. 110, 1150-1154.

Kim K S and Bae S H (2000) The effect of mitomycin-C on the function of corneal endothelial cells in rabbit. Korean J. Ophthalmol. 41, 10471053.

Kim K S, Lee S Y, and Kim J H (2002) The inhibitory effects of mitomycin-C on the development of proliferative vitreoretinopathy. J. Korean Soc. 43, 204-212.

Kim S J, Lee M H, Kim E H, and Lee J S (2008) Corneal opacity caused by LASEK with improper high-concentrated mitomycin-C. J. Korean Ophthalmol. Soc. 49, 1525-1531.

Kim Y T and Chung W S (2002) The effect of mitomycin C in endonasal dacryocystorhinostomy. J. Korean Ophthalmol. Soc. 43, 728-732.

Kuhnau J (1976) The flavonoids: a class of semi-essential food components: their role in human nutrition. World Rev. Nutr. Diet. 24, 117-191.

Lisi S, Botta R, Lemmi M, Sellari-Franceschini S, Altea M A, Sisti E, Casini G, Nardi M, Marcocci C, Pinchera A, and Marinò M (2010) Quercetin decreases proliferation of orbital fibroblasts and their release of hyaluronic acid. J. Endocrinol. Invest. 34, 521-527.

Majmudar P A, Forstot S L, Dennis R F, Nirankari V S, Damiano R E, Brenart R, and Epstein R J (2000) Topical mitomycin-C for subepithelial fibrosis after refractive corneal surgery. Ophthalmology 107, 89-94.

Natto M V, Mohan R R, Ambrósio R Jr, Hutcheon A E, Zieske J D, and Wilson S E (2005) Wound healing in the cornea: a review of refractive 
surgery complications and new prospects for therapy. Cornea $\mathbf{2 4}$ 509-522.

Reiterer G, Toborek M, and Hennig B (2004) Quercetin protects against linoleic acid-induced porcine endothelial cell dysfunction. J. Nutr. 134, 771-775.

Rubinfeld R S, Pfister R R, Stein R M, Foster C S, Martin N F, Stoleru S, Talley A R, and Speaker M G (1992) Serious complications of topical mitomycin-C after pterygium surgery. Ophthalmology 99, 1647-1654.

Smith S, D'Amore P A, and Dreyer E B (1994) Comparative toxicity of mitomycin $\mathrm{C}$ and 5-fluorouracil in vitro. Am. J. Ophthalmol. 118, 332-
337.

Xu H, Liu S, Xia X, Huang P, Wang P, and Wu X (2001) Mitomycin C reduces haze formation in rabbits after excimer laser photorefractive keratectomy. J. Refract. Surg. 17, 342-349.

Zyzak L L, MacDonald L M, Batova A, Forand R, Creek K E, and Pirisi L (1994) Increased levels and constitutive tyrosine phosphorylation of the epidermal growth factor receptor contribute to autonomous growth of human papillomavirus type immortalized human keratinocytes. Cell Growth Differ. 5, 537-547. 